\title{
The Teacher's Torts and Development of the Rule of Law in Education
}

\author{
Fanlei Meng ${ }^{1, a}$ \\ ${ }^{1}$ Feixian School, Linyi University, Feixian, Shandong, P.R.China \\ a lydxmfl@126.com
}

\begin{abstract}
what makes teacher's torts in primary and secondary schools special is that it is usually hard to detect and will do great harm to students physically, mentally and morally. It is necessary for teachers to improve teaching method, study legal knowledge, strengthen their legal consciousness, operate on education according to laws, intensify legal ideology in education, and exercise teacher's power on the basis of respecting students' legal rights,_which may decrease or stop the phenomenon of teacher's torts ever happening again.
\end{abstract}

Keywords: Teachers; torts; The rule of law in education

\section{Introduction}

In the educational practices of primary and secondary school, teacher's infringement on student's personal rights is drawing more and more social attention, and has became a little bit hot problem in realm of pedagogy in recent years. To learn about and avoid torts in our daily life is guarantee for teacher to complete teaching task better. Besides, we should learn about the negative consequences we should bear and the way we take responsibility for the torts, so as to make the harm caused by torts definite.

\section{The traits of teacher's torts}

2.1. Most of teachers based their torts on educating students, while the society and parents rarely will equate teacher's improper actions to torts because of good intention of teachers, usually they tend to turn a blind eye on such things. Even encountered aggravated torts, rather than treat it as a infringement of rights legally, people tend to regard it as a matter of professional ethics and personal morality, let alone investigating the actor's legal responsibility[1].

2.2. The capacity for conduct of students is not equal to teacher's, which will affect the definition of torts. The underage students are too young to protect themselves well, to distinguish right from wrong. Besides, being deeply influenced by Chinese tradition of keeping "absolute authority of teachers", students rarely judge teacher's acts from the perspective of torts. Some teachers also take their torts for

guaranteed or not even realize their infringement in students' rights for that students are slow to response to the torts and lack the awareness of rights[2].

2.3. Being deeply influenced by traditional culture and social conception, both teacher and student still cannot approve of tolerance and democracy's existence in teaching activities. In a word, the lack of democratic conscious in our society and the emphasis on "absolute dignity of teachers" in our traditional culture make it quite difficult to popularize democracy and equality on our campus. In teaching management, teachers tends to be gentle and stern, to use carrot as well as stick, the way that students do not like but are used to.

2.4 .The reason is diverse, while the underlying reason is that at present educational and teaching activities serve the test, the grades determines everything. The pressure of schoolwork and job stress make teachers to focus more on improving students' grades, then it may be unavoidable for them to treat students in a rude manner[3]. In such circumstances, to think about whether to select a scientific and rational way or not or how to select are both inappropriate to some extent.

\section{The harm caused by teacher's torts}

Teacher's torts can do harm on students physically, mentally and morally.

\subsection{Teacher's torts harm students physically}

Primary and secondary students are in their special stage of growth, the development of body parts is still immature, their body cannot handle so much corporal punishment from teacher such as over burned homework, long time-out in class, which has affected their body growth. And what's more is that some teachers go to extremes in corporal punishment, and cause students' physical injury even physical disabled.

\section{2 .Teacher's torts harm students mentally}

The mental harmfulness of teacher's torts on students is much more serious than physical harmfulness. Psychologically, the state of primary and secondary students 
is not stable, they are emotionally vulnerable, and are in the stage of building up self-esteem. Teacher's irony, abuse and discrimination will injured student's self-esteem seriously: on the one hand, the introverted students tends to become more and more self-contemptuous and even become withdrawn. On the other hand, the extraverted students tend to get psychological compensation from attacking other students or insulting their parents. If suffering from scold or corporal punishment in long term, students will mostly abandon themselves.

\section{3 . Teacher's torts harm students morally}

Being representative of social morality, teacher's acting as an example will help to promote the development of students' morality. Students will learn from teachers the concepts and behaviors confirms to the society, and stay away from the ones which rejects social morality. Teacher's torts will make students puzzled on moral concepts or behaviors, even give them passive thoughts about it[4]. For instance, have a passion for labor is virtue of China, while some teachers use it as a punishment, like punishing a student to do the cleaning all by himself(herself), which makes students view labor as disgraceful or even disgusting things.

\section{Strengthen the rule of law in education, promote the development of students}

To show respect for students' rights and promote the development of students, we can strength the rule of law from following aspects.

4.1. Enhance and complete the existing legal system.

Primary and secondary students are in their special stage of growth, from this point, to promote students' development, our government have formed such legal systems that consists of constitutional clauses on education, Education Law, Compulsive Law, and administrative regulations on education promulgated by all levels of government. Besides, there are also special laws such as Juvenile Protection Law of People's Republic of China, the Law of Preventing Minors from Committing Crimes to protect the physical and mental development of juveniles legally.

However, it is worth noting that all of above-mentioned laws are "soft-laws", the reason is as follows: firstly, instead of using rigorous legal terms like "ban" or "must" that can reflect the authority of laws, it is filled with words such as "should", "ought to", " encourage" and so on[5]. Secondly, there is only principled directions instead of regulations in actual operation. Thirdly, the rules in legal responsibility is not concrete enough in detail.

So, to promote the development of students, the first obvious thing to do is to complete the existing laws related to education, and change the situation of "soft-laws".
4.2. Strengthen the advertisement in role of rule of law in education

Law is the behavioral regulations enacted by national legislature and guaranteed by the regime. Because of its compulsory feature, people tend to summarize the role of law into punishing, warning and preventing illegal behaviors, and even equal the "rule" in "rule of law" to regulate, which means regulate school and students in accordance with law negatively. Supported by such kind of view, some teachers replace "law" with "punishment", which also aroused the frequent happening of teacher's torts like corporal punishment, sarcasm, etc[6].

As a result, we must strengthen the advertisement of education law, make students and teachers realize the protective and preventive function of education laws. Comprehensively speaking, the "rule" in "rule of law" means supervision and service, instead of simply a form of regulation.

4.3. Strengthen teacher's legal consciousness and reduce torts

It is undeniable that the reason for most of teacher torts happened in primary and secondary school is that the quality of teacher is low, most of them do not have strong legal consciousness, some even are unaware of their illegal behaviors. So strengthen teacher's legal consciousness is important for reducing torts and promoting the development of students.

- 4.3.1 Enhance teacher's knowledge about student's rights. Being influenced by traditional culture, regardless of legal rights of students, who are usually viewed as the educated and the managed, teachers tend to place much more emphasis on disciplinary action. In spite of good intentions, teacher's ignorance of student's rights equals to torts. Enhance teacher's knowledge about student's rights will help to reduce torts.

- 4.3.2 Enhance teacher's learning on relevant legal articles. Although teachers have some knowledge of relevant legal articles, the right to education and privacy more or less, they may know little or nothing on other rights of students. However, because of legal ignorance, some teachers treat their torts as moral issues even when they know well that they have infringed student's rights, without thinking about legal responsibility they should taken, they make secondtime torts[7]. So the Constitution ,Education Law, Compulsory Law, and Juvenile Protection Law of People's Republic of China are important contents to be included in pre-service training and continuing education, to make every teacher realized that student's rights can't be infringed and responsibility should be taken when student's rights are infringed, so as to reduce torts. 
- 4.3.3 Enhance learning on teachers-related cases. Teacher torts happens frequently in primary and middle schools, especially corporal punishment, which has caused severe damage to students physically and mentally. Some teacher torts even makes criminal offence. Study on such cases will help teachers to have a better knowledge of student's legal rights and the consequence brought by teacher torts.

4.4. Foster student's self protective consciousness by enhancing their knowledge on legal rights of themselves

In primary and secondary schools, the behavioral object of teacher torts is underage student, who does not have full capacity for conduct. They have little knowledge of their legal rights.

In the meanwhile, influenced by our traditional culture, which emphasis absolute dignity of teachers, majority of students can't realize that their rights are infringed after teacher torts, even realized the torts, they are still too young to protect themselves from infringement. So this explains why should we enhance student's knowledge on legal rights of themselves. For instance, open exhibitions themed "educational laws" in pictures or lectures in primary and secondary school, offer legal course in middle school and focus on the teaching of student's rights, etc. students should also be educated to pick up the weapon of law to protect their legal rights.

\subsection{Strengthen the supervision of education laws}

Supervision guarantees the enforcement of law. To a large extent, unlawful practices like teacher torts are not looked into is because of the lack of powerful supervision[8]. The society tend to condemn teacher torts morally instead of considering it legally; considering teacher's good intention, the parents do not have profound understanding of teacher torts and attribute all the mistakes to their children; the school merely give teachers criticism of education after teacher torts happened.

\section{CONCLUSIONS}

Although teacher torts is not very common, its harmfulness should not be ignored for that it is closely related to student's daily life and some of torts may cause wounds difficult to heal in their tiny souls, so teachers and school administrators should pay great attention to such kind of phenomenon. Thus teachers should improve their teaching methods, study education laws, enhance their legal consciousness, managing education by law comprehensively, strengthen the rule of law in education, and exercise their rights on the basis of respecting student's legal rights, so as to reduce or end teacher torts.

\section{Acknowledgment}

The authors wish to give their sincere thanks to the editor and the anonymous referees for their valuable suggestions and helpful comments which improved the presentation of the paper.

\section{References}

[1] Li Min, The Era of rights[D]. East China Normal University,2009.

[2] Wu Dikai, Wu Guangzheng, Brief Review of Education Law[J], 3 Theoretic Observation, 2001.

[3] Yu Hongwei, The Cause and Countermeasure Analysis of the Infringement of Students' Right[D].Capital Normal University, 2007.

[4] Zhang Limei, The Survey and Analysis of Teachers' and Students' Understanding of Middle School Students' Legal Right-How Far Away Is It From Us To Respect Students' Right[J]. 11 Liaoning Education Research,2000.

[5] Wang Jingbin, Tang Jigeng, Brief Discussion of Ruling College by Law $[\mathrm{J}]$. 2 Journal of Northeast Normal University,2000.

[6] Chen Peiya, The Predicament and Countermeasure Analysis of Educational Legislation in Primary and Secondary schools[D]. Soochow University,2009.

[7] Liu Hangling, Su Zhengwang, The Survey and Analysis of Corporal Punishment In Primary and Secondary schools[J]. 3 Journal of The Chinese Society of Education, 1997.

[8] Zha Mingxiang, Enhancing The Supervision and Enforcement of Education Law[J].3 Journal of Anqing Teachers College(Social Science Edition),2000. 